\title{
Mode of anesthesia and clinical outcomes of patients undergoing Cesarean delivery for invasive placentation: a retrospective cohort study of 50 consecutive cases \\ Mode d'anesthésie et issues cliniques des patientes subissant un accouchement par césarienne en raison d'une placentation envahissante: une étude de cohorte rétrospective de 50 cas consécutifs
}

\author{
Nhathien Nguyen-Lu, BMBS · Jose Carlos Almeida Carvalho, MD, PhD • \\ John Kingdom, MD • Rory Windrim, MD • Lisa Allen, MD • \\ Mrinalini Balki, MBBS, MD \\ Received: 25 January 2016/Revised: 23 May 2016/Accepted: 4 July 2016/Published online: 21 July 2016 \\ (C) Canadian Anesthesiologists' Society 2016
}

\begin{abstract}
Purpose Invasive placentation is one of the most important causes of postpartum hemorrhage and Cesarean hysterectomies (CHyst). The optimal mode of anesthesia in the management of these patients remains uncertain. The purpose of this study was to review the impact of mode of anesthesia on maternal and neonatal outcomes in women with invasive placentation undergoing Cesarean delivery (CD).

Methods $A$ retrospective cohort study was conducted in women with invasive placentation who delivered at our hospital during 2000-2012. Patients' charts and electronic health records were searched for relevant data, including obstetric and anesthetic procedures, blood loss, use of
\end{abstract}

Disclosures: This paper was presented at the 45th Annual Meeting of the Society for Obstetric Anesthesia and Perinatology, Puerto Rico, USA, April 24-28, 2013 and also at the Canadian Anesthesiologists' Society Annual Meeting, Calgary, Canada, June 21-24, 2013. Mrinalini Balki is supported by a Merit award from the Department of Anesthesia, University of Toronto, ON, Canada.

N. Nguyen-Lu, BMBS - J. C. A. Carvalho, MD, PhD

M. Balki, MBBS, MD ( $\square)$

Department of Anesthesia and Pain Management, Mount Sinai Hospital, University of Toronto, 600 University Avenue, Room 19-104, Toronto, ON M5G 1X5, Canada e-mail: mrinalini.balki@uhn.ca

J. C. A. Carvalho, MD, PhD

J. Kingdom, MD $\cdot$ R. Windrim, MD $\cdot$ L. Allen, MD

M. Balki, MBBS, MD

Department of Obstetrics and Gynaecology, Mount Sinai

Hospital, University of Toronto, Toronto, ON, Canada resuscitation fluids, and neonatal and maternal complications. Based on the initial planned mode of anesthesia (i.e., general or regional) for $C D$, comparisons were made between groups for maternal blood loss and transfusion, respiratory complications, and neonatal Apgar scores.

Results $O f$ the 50 women with confirmed invasive placentation, 25 (50\%) underwent elective CD, while the remaining 25 (50\%) had unplanned CD; 36 (72\%) required CHyst. Surgery for 34 (68\%) patients commenced under regional anesthesia (RA), and surgery for $16(32 \%)$ patients commenced under general anesthesia (GA). In women who received GA vs $R A$, there was no difference in mean (SD) blood loss [3,206 $(3,777) \mathrm{mL}$ vs 1,906 (1096) $\mathrm{mL}$, respectively; mean difference, 1,300 $\mathrm{mL}$; $95 \%$ confidence interval (CI), -739 to 3,339 $\mathrm{mL} ; P=0.20]$ or median [IQR] blood transfusion (4 [0-6] units vs 2 [0-4] units, respectively; median difference, 2 units; $95 \%$ CI, 0 to 4 units; $P=0.16)$. In neonates of women who received only $R A$ before delivery vs those who received GA prior to delivery, significantly higher median [IQR] Apgar scores were observed at both one minute (8 [8-9] vs 3 [0-5], respectively; median difference, 5; 95\% CI, 3 to 8; $\mathrm{P}<$ 0.001) and five minutes (9 [9-9] vs 7 [0-9], respectively; median difference, 2; 95\% CI, 1 to 9; $P<0.001)$. Postoperative respiratory complications were more common with GA (6\%) than with RA $(0 \%)(P=0.03)$.

Conclusion Having safely performed two-thirds of our cases of CHyst under RA, our study suggests that RA, when compared with GA, is associated with no differences in blood loss or blood transfusion, superior neonatal 
outcome, and fewer respiratory complications. This suggests that RA can be considered a primary mode of anesthesia for such cases.

\section{Résumé}

Objectif La placentation envahissante est l'une des principales causes d'hémorragie postpartum et d'hystérectomie lors d'une césarienne. Le meilleur mode d'anesthésie pour prendre en charge ces patientes demeure incertain. L'objectif de cette étude était de passer en revue l'impact du mode d'anesthésie sur les issues maternelles et néonatales chez les femmes présentant une placentation envahissante et subissant un accouchement par césarienne. Méthode Une étude de cohorte rétrospective a été réalisée auprès de femmes présentant une placentation envahissante et ayant accouché dans notre hôpital entre 2000 et 2012. Les dossiers des patientes et leurs dossiers de santé électroniques ont été étudiés pour en tirer les données pertinentes, notamment les interventions obstétricales et anesthésiques, les pertes sanguines, l'utilisation de liquides de réanimation, et les complications néonatales et maternelles. Selon le mode d'anesthésie initialement planifié (soit une anesthésie générale ou régionale) pour la césarienne, on a comparé les pertes sanguines et les transfusions maternelles, les complications respiratoires et les scores Apgar des nouveau-nés entre les groupes.

Résultats Parmi les 50 femmes présentant une placentation envahissante confirmée, 25 (50\%) ont subi une césarienne planifiée, alors que chez les 25 (50\%) autres femmes, la césarienne n'était pas planifiée; 36 (72\%) ont nécessité une hystérectomie. La chirurgie de 34 (68\%) patientes a commencé sous anesthésie régionale (AR), et la chirurgie des 16 (32\%) autres patientes a débuté sous anesthésie générale (AG). Chez les femmes ayant reçu une $A G$ vs une AR, aucune différence n'a été observée en matière de pertes sanguines moyennes (ÉT) [3206 (3777) mL vs 1906 (1096) mL, respectivement; différence moyenne, $1300 \mathrm{~mL}$; intervalle de confiance (IC) $95 \%$, -739 à $3339 \mathrm{~mL} ; P=0,20]$ ou de transfusion sanguine médiane [ÉIQ] (4 [0-6] unités vs 2 [0-4] unités, respectivement; différence médiane, 2 unités; IC $95 \%, 0$ à 4 unités; $P=0,16)$. Chez les nouveau-nés de femmes ayant reçu une AR seulement avant l'accouchement vs celles ayant reçu une AG avant l'accouchement, des scores Apgar médians [ÉIQ] significativement plus élevés ont été observés à une minute (8 [8-9] vs 3 [0-5], respectivement; différence médiane, 5; IC $95 \%, 3$ à $8 ; P<0,001)$ et à cinq minutes (9 [9-9] vs 7 [0-9], respectivement; différence médiane, 2, IC $95 \%, 1$ à 9; $P<0,001)$. Les complications respiratoires postopératoires étaient plus fréquentes avec l'AG $(6 \%)$ qu'avec l'AR $(0 \%)(P=0,03)$.

Conclusion Nous avons réalisé deux tiers de nos cas de césariennes couplées à une hystérectomie en toute sécurité avec une anesthésie régionale. Par conséquent, selon notre étude, l'anesthésie régionale, par rapport à l'anesthésie générale, n'est associée à aucune différence en matière de perte et de transfusion sanguine, mais à de meilleures issues néonatales et une quantité moindre de complications respiratoires. Ces observations suggèrent que l'anesthésie régionale peut être envisagée comme mode principal d'anesthésie dans de tels cas.

Invasive placentation remains one of the most significant underlying causes of primary postpartum hemorrhage and is an increasingly common indication for Cesarean hysterectomy (CHyst). ${ }^{1-3}$ Results of a recent study in the United States revealed that the overall frequency of morbidly adherent placenta was one per 731 births $(95 \%$ confidence interval $[\mathrm{CI}], 1 / 632$ to $1 / 866)$ during the periods 2008 and 2011. ${ }^{1}$ The United Kingdom (UK) Obstetric Surveillance System estimated the incidence of peripartum hysterectomy to control hemorrhage to be 40.6 (95\% CI, 36.3 to 45.4 ) per 100,000 deliveries, $30 \%$ of which were associated with a morbidly adherent placenta. $^{2}$ The incidence of invasive placentation in the UK has increased in the past 50 years from $0.04-0.9 \%$, possibly due to an increase in the rate of uterine surgeries being performed. ${ }^{4}$

Abnormal placentation occurs when the placental villi attach directly to the myometrium rather than to the uterine decidua (accreta), with potential invasion into the uterine wall (increta) or through the serosa into surrounding organs (percreta). ${ }^{5}$ The pathogenesis of this condition is most likely due to deficient areas of decidua and underlying myometrium in the anterior lower uterine segment, commonly due to one or more prior low transverse uterine incisions for Cesarean deliveries (CDs). ${ }^{6}$ Nevertheless, recent evidence suggests that invasive placentation can also occur in nulliparous women and in those without any prior CDs. ${ }^{1}$ This highlights the importance of recognizing that such cases can occur even in women otherwise thought to be at very low risk of developing this complication.

Previous studies have been conducted in our institution to investigate the obstetric outcomes and anesthetic management in patients with invasive placentation. Thus far, however, there is a lack of studies to determine the impact of the mode of anesthesia on maternal/neonatal morbidity. ${ }^{7,8}$ The purpose of this study was to report the impact of the mode of anesthesia (i.e., regional anesthesia 
vs general anesthesia) on maternal and neonatal outcomes in women with known invasive placentation over a 12-year period (2000-2012) in our institution.

\section{Methods}

This retrospective cohort study was conducted at Mount Sinai Hospital in Toronto, Canada following Research Ethics Board approval (REB \#12-0214-C; September, 2, 2012). The study included deliveries from January 1, 2000 until December 31, 2012. The patient volume at our hospital is approximately 7,500 deliveries per year. Our hospital serves as both a primary and a referral obstetrical centre and is equipped with a Level 3 neonatal nursery. The search terms "placenta accreta", "placenta increta" or "placenta percreta", "placenta previa", and "uterine artery embolization" were identified in the ICD-9 (2000-2001) and ICD-10 (2001-2012) codes to search health records to identify patients to be included in this study. In addition, the obstetric registry as well as the obstetric magnetic resonance imaging (MRI) and perinatal pathology databases were cross-checked with the hospital electronic delivery record system (OB TraceVue System; Philips, MA, USA) to identify patients.

Inclusion criteria were delivery at Mount Sinai Hospital with ultrasound and /or MRI evidence of placental invasion into myometrium ${ }^{9}$ and confirmation with histopathology in cases undergoing CHyst or with surgical findings in cases undergoing CD only. The health record files were manually reviewed to confirm appropriate inclusion into the study.

Patients were classified into two groups, regional anesthesia (RA) or general anesthesia (GA), based on the planned mode of anesthesia they received for the case. Patients were included in the RA group if they received an epidural or combined spinal-epidural (CSE) as sole anesthetics or if their regional technique was converted to GA (most commonly due to intraoperative hemodynamic instability). In the latter case, the patients were analyzed by the intention-to-treat method under the RA group. The GA group consisted of patients who received GA as either a sole anesthetic or along with epidural catheter placement for postoperative analgesia. The GA group also included those who received epidural anesthetics until delivery and planned GA immediately after delivery.

Patient demographics and anesthetic intervention data were collected, including dosage of induction agents, use of vasopressors, and the epidural drugs used for $\mathrm{CD}$. Obstetric data and diagnostic imaging reports were reviewed, and surgical, interventional radiology (IR), and anesthesia consultations and procedures were checked. The surgical technique consisted of either CHyst or CD with a "conservative approach", whereby the abnormally adherent placenta was left in situ following the delivery of the fetus. The data on estimated blood loss (EBL) as recorded on the anesthetic record, use of blood products, duration of surgery, as well as early and late complications were recorded. The data on postoperative patient disposition, including length of hospital stay, were also collected in addition to neonatal outcome data (Apgar scores at one and five minutes).

If time allows, all patients at our institution with suspected placenta increta or percreta receive preoperative percutaneous balloon insertion (5 French 8.5-mm diameter occlusion balloon catheters; Boston Scientific, Natick, MA, USA) into the anterior division of the internal iliac artery. Postoperatively, as part of protocol, patients routinely return to the radiology suite for angiography to assess the need for embolization of the vessels with an absorbable gelatin sponge $\left(\right.$ Gelfoam $^{\circledR}$; Pfizer, NY, USA). The balloon catheters are removed once the IR assessment/treatment is completed, and one femoral sheath is left in place for 24 hours in case the patient exhibits signs of de novo bleeding and a repeat angiography is immediately required.

In patients receiving RA, a lumbar epidural catheter was inserted prior to balloon insertion for either surgical or postoperative analgesia. The catheter was then tested using $2 \%$ lidocaine $3 \mathrm{~mL}$ or an epidural electrical stimulation test (Tsui test) ${ }^{10}$ before the patient was transferred to the IR department. The patients were positioned supine with a $30^{\circ}$ left-lateral tilt throughout the balloon catheter insertion and during the $\mathrm{CD}$ until the birth of the fetus. When used for the surgical procedure as a primary technique, the epidural catheter was loaded with $2 \%$ lidocaine $20-25 \mathrm{~mL}$ with 1:200,000 epinephrine or $0.5 \%$ bupivacaine in divided doses, along with fentanyl $50 \mu \mathrm{g}$ to achieve a bilateral block level (tested with ice) at T4. Subsequent top-ups varied from 10-20 $\mathrm{mL}$ of $0.25 \%$ bupivacaine in divided doses with the use of fentanyl 50-100 $\mu \mathrm{g}$.

For GA, the choice of drugs used for rapid sequence induction and maintenance of anesthesia was at the discretion of the consultant anesthesiologist. This included the use of thiopental, propofol, or ketamine, with fentanyl for induction of anesthesia. Muscle relaxation was accomplished with either suxamethonium or rocuronium. Maintenance of GA during the case was achieved mainly with sevoflurane or desflurane at 0.7-1.0 minimum alveolar concentration, with some cases guided by the use of bispectral index monitoring for depth of anesthesia. In addition to routine monitoring, a radial arterial catheter was inserted for invasive blood pressure monitoring and blood gas sampling.

For postoperative analgesia, the majority of women received epidural morphine $2.5 \mathrm{mg}$ at the end of the 
surgery, followed in some cases by an epidural infusion of $0.125 \%$ bupivacaine and fentanyl $2 \mu \mathrm{g} \cdot \mathrm{mL}^{-1}$ at a rate of 10 $\mathrm{mL} \cdot \mathrm{hr}^{-1}$ for $24 \mathrm{hr}$. Those without epidural catheters received intravenous patient-controlled analgesia with morphine.

\section{Statistical analysis}

Data are presented as mean (standard deviation [SD]), median (interquartile range [IQR]), and frequencies, as appropriate. Comparisons between GA and RA groups were performed using Fisher's exact, Chi square and Student's $t$ tests, assuming unequal variance between samples (Welch's $t$ test). Between-sample median differences were estimated using the Hodges-Lehmann method.

Univariable logistic regression models were created to determine factors associated with increased odds of receiving any transfusion of packed red blood cells (PRBCs). A second analysis was done using univariable linear regression models to determine factors associated with an increase in the number of units of PRBCs transfused. All reported $P$ values are two sided. All statistical analyses were performed using SAS® v9.3 (The SAS Institute, Cary, NC, USA).

\section{Results}

Fifty-five women were identified with invasive placentation, 50 of whom had confirmed diagnosis based on surgical findings or histopathology. Of these, 34 women received RA and 16 received GA (Figure). Patient demographics and the percentages of women who presented with risk factors for invasive placentation are shown in Table 1. The differences in various outcomes based on the mode of anesthesia are shown in Table 2.

Anesthetic technique and monitoring

Of the 34 women classified under RA, 31 received an epidural or CSE as a sole anesthetic, and in three cases, epidural anesthesia was converted to GA intraoperatively due to hemodynamic instability from excessive bleeding. These three cases were included in the RA group. Of the 16 women classified under GA, six received GA exclusively, while ten received planned GA along with epidural analgesia (GA before delivery, $n=8$; GA after delivery, $n=2$ ) (Figure 1). All patients with an epidural in situ in the RA group $(n=34)$ and in the GA group after delivery $(n=$ 2) received variable doses of either $2 \%$ lidocaine or $0.5 \%$ bupivacaine and fentanyl preoperatively for surgical anesthesia. Some patients received additional doses of
Figure Mode of anesthesia in women with invasive placentation. $\mathrm{CD}=$ Cesarean delivery; $\mathrm{CSE}=$ combined spinal-epidural; D \& $\mathrm{E}=$ dilation and evacuation; $\mathrm{GA}=$ general anesthesia; ITT $=$ intention to treat

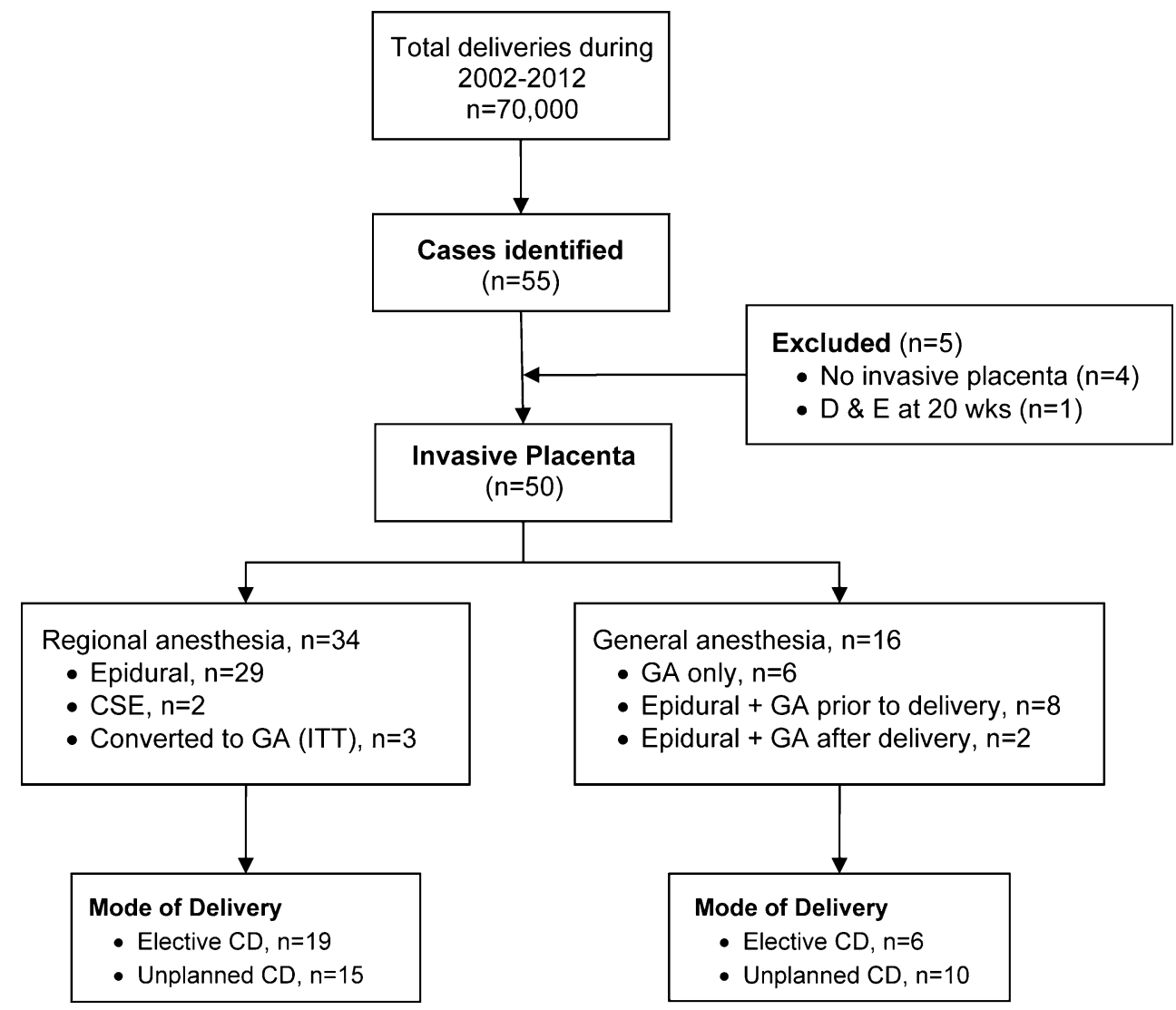


Table 1 Patient demographics and risk factors for invasive placentation

\begin{tabular}{|c|c|c|c|}
\hline & $\begin{array}{l}\text { Overall } \\
n=50\end{array}$ & $\begin{array}{l}\text { Regional Anesthesia } \\
n=34\end{array}$ & $\begin{array}{l}\text { General Anesthesia } \\
n=16\end{array}$ \\
\hline \multicolumn{4}{|l|}{ Patient demographics } \\
\hline Age (yr) & $34.0(5.7)$ & $33.6(5.2)$ & $34.8(6.8)$ \\
\hline Gravida & $4(3-5)$ & $4(3-5)$ & $4(3-5)$ \\
\hline Para & $2(1-2)$ & $2(1-3)$ & $2(1-2)$ \\
\hline \multicolumn{4}{|l|}{ Risk factors } \\
\hline Age $>35(y r)$ & $22(44 \%)$ & $15(44 \%)$ & $7(44 \%)$ \\
\hline Previous CD & $46(92 \%)$ & $31(91 \%)$ & $15(94 \%)$ \\
\hline Placenta previa & $47(94 \%)$ & $32(94 \%)$ & $15(94 \%)$ \\
\hline Previous uterine surgery & $26(52 \%)$ & $17(50 \%)$ & $9(56 \%)$ \\
\hline \multicolumn{4}{|l|}{ Diagnosis on histopathology } \\
\hline Percreta & $24(48 \%)$ & $19(56 \%)$ & $5(31 \%)$ \\
\hline Increta & $15(30 \%)$ & $7(21 \%)$ & $8(50 \%)$ \\
\hline Accreta & $11(22 \%)$ & $8(24 \%)$ & $3(19 \%)$ \\
\hline
\end{tabular}

Values are expressed as mean (standard deviation), median (range), or $n(\%)$

$\mathrm{CD}=$ Cesarean delivery

$0.125-0.25 \%$ bupivacaine $5-10 \mathrm{~mL}$ with fentanyl 2.5 $\mu \mathrm{g} \cdot \mathrm{mL}^{-1}$ intraoperatively. At the end of the operation, epidural morphine $2.5 \mathrm{mg}$ was administered to all patients with functioning epidurals for postoperative analgesia.

In cases of GA, half of the women $(n=8)$ received thiopental as an induction agent (median [IQR], 300 [300$394] \mathrm{mg})$, while the remaining half $(n=8)$ received propofol (200 [150-200] $\mu \mathrm{g})$. Additionally, midazolam (3 [2-4] mg) was given in two cases and ketamine (60 [45-75] $\mathrm{mg}$ ) was given in two cases during induction. Fentanyl $(150$ [100-200] $\mu \mathrm{g})$ was used as an adjunct at induction in 12 cases. Intubation was facilitated by suxamethonium $(100$ [100-130] $\mathrm{mg})$ and rocuronium (60 [50-70]) in 11 $(69 \%)$ and five $(31 \%)$ cases, respectively.

A radial arterial catheter was inserted in 45 women to monitor arterial pressure, while five had a femoral artery cannula transduced to serve as an alternative. Phenylephrine was the most commonly used vasopressor for the treatment of intraoperative hypotension. The median [IQR] dose of phenylephrine was 1,100 [300$1,500] \mu \mathrm{g}$ in the GA group and 900 [575-1,225] $\mu \mathrm{g}$ in the RA group. Central venous catheters were inserted in only four women, all of whom experienced a substantial amount of blood loss after the delivery of the fetus.

\section{Surgical and radiological approach}

Twenty-five (50\%) women underwent an elective $\mathrm{CD}$, while the remaining $25(50 \%)$ presented for unplanned $\mathrm{CD}$ due to an immediate threat to the life of the mother (23 patients, $92 \%$ ) or the fetus (two patients, $8 \%$ ). The majority of unplanned CDs were a result of antepartum hemorrhage
(APH) (Figure 1). Within the group of 18 patients who had an emergency CD due to bleeding, the majority (16 patients, $89 \%$ ) were performed under RA despite the presentation of APH. Two patients (8\%) had emergency surgery for fetal distress, with fetal decelerations and shift or reversal of end diastolic flow on umbilical artery Doppler ultrasound. One of these patients received RA and the other received GA. The remaining five patients (20\%) were classified as "urgent" $\mathrm{CD}$ because of pain due to spontaneous rupture of membranes and contractions; all of these patients received RA. Overall, 36 (72\%) patients underwent $\mathrm{CHyst}$. There was no difference in the rate of CHyst between the groups (Table 2). The mean (SD) time in the operating room was similar in patients in the GA vs RA groups [178 (88) min vs 105 (33) min, respectively; $P=0.07]$.

Forty-four women $(88 \%)$ had internal iliac artery occlusion balloons inserted preoperatively, $38(86 \%)$ of whom required inflation intraoperatively, and $33(75 \%)$ underwent postoperative embolization. The RA group had 32/34 (94\%) patients with balloons inserted, 29 (91\%) of which were inflated. In contrast, the GA group had only 12/ $16(75 \%)$ patients with balloons inserted, nine $(75 \%)$ of which were inflated. There were no significant differences between the RA and GA groups regarding the requirement for immediate postoperative embolization (Table 3).

\section{Fluid resuscitation}

In women who received GA vs RA, there was no difference in mean (SD) EBL $[3,206(3,777) \mathrm{mL} v \mathrm{~s}$ $1,906(1,096) \mathrm{mL}$, respectively; mean difference, 1,300 $\mathrm{mL} ; 95 \% \mathrm{CI},-739$ to $3,339 \mathrm{~mL} ; P=0.20$ ] or median 
Table 2 Anesthetic and surgical management of women with invasive placentation

\begin{tabular}{|c|c|c|c|c|}
\hline & $\begin{array}{l}\text { Overall } \\
n=50\end{array}$ & $\begin{array}{l}\text { Regional Anesthesia } \\
n=34\end{array}$ & $\begin{array}{l}\text { General Anesthesia } \\
n=16\end{array}$ & $P$ Values \\
\hline \multicolumn{5}{|l|}{ Resuscitation } \\
\hline Estimated blood loss (mL) & $2,322(2,356)$ & $1,906(1,096)$ & $3,206(3,777)$ & 0.20 \\
\hline Median [IQR] & $2,000[1,000-2,500]$ & $1,850[1,000-2,000]$ & $2,000[950-3,500]$ & \\
\hline Blood transfusion & $29(58 \%)$ & $18(53 \%)$ & $11(69 \%)$ & 0.37 \\
\hline Packed RBC (unit)* & $2(0-15)$ & $2(0-8)$ & $4(0-15)$ & 0.07 \\
\hline Median [IQR] & $2[0-4]$ & $2[0-4]$ & $4[0-6]$ & \\
\hline Fresh Frozen Plasma (unit)* & $0(0-12)$ & $0(0-4)$ & $0(0-12)$ & 0.04 \\
\hline Platelets (pool)* & $0(0-8)$ & $0(0-1)$ & $0(0-8)$ & 0.35 \\
\hline Cryoprecipitate (pool)* & $0(0-16)$ & $0(0-0)$ & $0(0-16)$ & 0.17 \\
\hline Crystalloid (mL) & $3,140(1,535)$ & $2,850(1,303)$ & $3,718(1,827)$ & 0.10 \\
\hline Colloid (mL) & $972(549)$ & $969(561)$ & $979(548)$ & 0.96 \\
\hline Arterial line insertion & $45(92 \%)$ & $30(91 \%)$ & $15(94 \%)$ & 1.00 \\
\hline CVC insertion & $4(8 \%)$ & $2(6 \%)$ & $2(13 \%)$ & 0.58 \\
\hline \multicolumn{5}{|l|}{ Interventional Radiology } \\
\hline Insertion of balloons & $44(88 \%)$ & $32(94 \%)$ & $12(75 \%)$ & 0.07 \\
\hline Inflation of balloons & $38(83 \%)$ & $29(91 \%)$ & $9(64 \%)$ & 0.04 \\
\hline Embolization of vessels & $33(66 \%)$ & $24(71 \%)$ & $9(56 \%)$ & 0.35 \\
\hline \multicolumn{5}{|l|}{ Uterotonic Drugs } \\
\hline Oxytocin & $24(48 \%)$ & $18(53 \%)$ & $6(38 \%)$ & 0.37 \\
\hline Ergometrine & $1(2 \%)$ & $0(0 \%)$ & $1(6 \%)$ & 0.32 \\
\hline Hemabate & $4(8 \%)$ & $3(9 \%)$ & $1(6 \%)$ & 1.00 \\
\hline \multicolumn{5}{|l|}{ Vasopressor Drugs } \\
\hline Phenylephrine & $41(82 \%)$ & $30(88 \%)$ & $11(69 \%)$ & 0.12 \\
\hline Ephedrine & $9(18 \%)$ & $7(21 \%)$ & $2(13 \%)$ & 0.70 \\
\hline Tranexamic Acid & $2(4 \%)$ & $1(3 \%)$ & $1(6 \%)$ & 0.54 \\
\hline Length of Operation (min) & $122(59)$ & $105(33)$ & $178(88)$ & 0.07 \\
\hline \multicolumn{5}{|l|}{ Surgical Technique } \\
\hline Conservative & $14(29 \%)$ & $10(30 \%)$ & $4(25 \%)$ & 1.00 \\
\hline Cesarean hysterectomy & $36(72 \%)$ & $24(71 \%)$ & $12(75 \%)$ & 1.00 \\
\hline \multicolumn{5}{|l|}{ Postoperative Disposition } \\
\hline ICU admission & $7(14 \%)$ & $4(12 \%)$ & $3(19 \%)$ & 0.67 \\
\hline Length of stay in ICU (days) & $1.6(0.8)$ & $2(0.8)$ & $1(0)$ & 0.09 \\
\hline Discharge from hospital (postoperative day) & $6.1(2.9)$ & $5.9(2.7)$ & $6.6(3.4)$ & 0.44 \\
\hline
\end{tabular}

Values are expressed as $n(\%)$, mean (standard deviation) or * median (range) unless otherwise specified

$\mathrm{CVC}=$ central venous cannulation; $\mathrm{ICU}=$ intensive care unit; $\mathrm{IQR}=$ interquartile range; $\mathrm{RBC}=$ red blood cells

[IQR] blood transfusion (4 [0-6] units vs 2 [0-4] units, respectively; median difference 2 units; $95 \% \mathrm{CI}, 0$ to 4 units; $P=0.16$ ). The GA group required a significantly greater number of units of fresh frozen plasma than the RA group $(P=0.04)$ (Table 2$)$. The three patients in the RA group whose anesthesia was converted to GA due to excessive blood loss and hemodynamic instability had an EBL of $2 \mathrm{~L}, 4 \mathrm{~L}$, and $6 \mathrm{~L}$ and required 4, 5, and 8 units of PRBCs, respectively.

There was a significantly higher risk of any PRBC transfusion in women undergoing unplanned CD (88\%) vs planned CD (7\%) [odds ratio (OR), 18.9; 95\% CI, 4.3 to
83.6; $P<0.001$ ] and CHyst (OR, 5.7; 95\% CI, 1.46 to 22.1; $P=0.01)$. General anesthesia was not associated with significantly more risk of blood transfusion (OR, 1.96; 95\% CI, 0.56 to $6.85 ; P=0.29$ ) compared with RA. Also, conversion from RA to GA was not associated with more risk of blood transfusion $(\mathrm{OR}, 1.9 ; 95 \% \mathrm{CI}, 0.5$ to $7.3 ; P=$ 0.34 ), but it was associated with an increase in the number of PRBC units transfused (Table 4). The rate of transfusion in the GA vs the RA group was $69 \%$ vs $53 \%$, respectively $(P=0.37)$. Various other factors associated with the risk of blood transfusion and the rates of PRBC transfusion are presented in Table 4. 
Table 3 Postoperative early and late complications in women with invasive placentation

\begin{tabular}{|c|c|c|c|c|}
\hline & $\begin{array}{l}\text { Overall } \\
(n=50)\end{array}$ & $\begin{array}{l}\text { Regional Anesthesia } \\
(n=34)\end{array}$ & $\begin{array}{l}\text { General Anesthesia } \\
(n=16)\end{array}$ & $P$ value \\
\hline \multicolumn{5}{|l|}{ Early Complications } \\
\hline Urological & $14(28 \%)$ & $7(21 \%)$ & $7(44 \%)$ & 0.11 \\
\hline Bowel obstruction & $2(4 \%)$ & $1(3 \%)$ & $1(6 \%)$ & 0.54 \\
\hline Respiratory & $3(6 \%)$ & $0(0 \%)$ & $3(19 \%)$ & 0.03 \\
\hline \multicolumn{5}{|l|}{ Hematological } \\
\hline DIC & $2(4 \%)$ & $2(6 \%)$ & $0(0 \%)$ & 1.00 \\
\hline Hematoma & $3(6 \%)$ & $2(6 \%)$ & $1(6 \%)$ & 1.00 \\
\hline Early hemorrhage & $3(6 \%)$ & $3(9 \%)$ & $0(0 \%)$ & 0.54 \\
\hline Postoperative fever & $5(10 \%)$ & $4(12 \%)$ & $1(6 \%)$ & 1.00 \\
\hline Surgical site infection* & $9(18 \%)$ & $6(18 \%)$ & $3(19 \%)$ & 1.00 \\
\hline Re-embolization & $4(8 \%)$ & $3(9 \%)$ & $1(6 \%)$ & 1.00 \\
\hline \multicolumn{5}{|l|}{ Radiological } \\
\hline Ischemia of limbs & $2(4 \%)$ & $1(3 \%)$ & $1(6 \%)$ & 0.54 \\
\hline Allergy to contrast & $1(2 \%)$ & $0(0 \%)$ & $1(6 \%)$ & 0.32 \\
\hline IR complications & $3(6 \%)$ & $2(6 \%)$ & $1(6 \%)$ & 1.00 \\
\hline \multicolumn{5}{|l|}{ Delayed Complications } \\
\hline Readmission to hospital & $9(18 \%)$ & $5(15 \%)$ & $4(25 \%)$ & 0.44 \\
\hline Late hemorrhage & $4(8 \%)$ & $3(9 \%)$ & $1(6 \%)$ & 1.00 \\
\hline Delayed hysterectomy & $4(8 \%)$ & $3(9 \%)$ & $1(6 \%)$ & 1.00 \\
\hline Late infection & $5(10 \%)$ & $3(9 \%)$ & $2(13 \%)$ & 0.65 \\
\hline Other & $3(6 \%)$ & $2(6 \%)$ & $1(6 \%)$ & 1.00 \\
\hline
\end{tabular}

DIC = disseminated intravascular coagulation; IR = interventional radiology. * Within 30 days of surgery

Respiratory complications include pulmonary atelectasis $(n=1)$, pulmonary embolism $(n=1)$, and hemoptysis with chest pain $(n=1)$

Postoperative disposition

Seven (14\%) women required admission to the intensive care unit (ICU). All received tracheal intubation and remained on ventilatory support for three to $45 \mathrm{hr}$, with a mean (SD) ICU stay of 1.6 (0.8) days. The remaining patients were transferred to the labour and delivery suite for overnight monitoring. The mean (SD) length of postdelivery hospital stay was 6.0 (2.8) days, with no difference between the RA and GA groups.

\section{Complications}

Table 3 displays the incidence of early and late complications encountered in both groups. There were no differences in the incidence of complications between mothers who had RA vs GA, with the exception of respiratory complications. All three women who developed respiratory complications (atelectasis, pulmonary embolism, and hemoptysis with chest pain not associated with pulmonary embolism) were in the GA group. Complications in the IR suite included vascular injury during catheterization in three patients. One of these patients had an iatrogenic rupture of the anterior division of the left internal iliac artery caused by the occlusion balloon, which resulted in massive hemorrhage and cardiac arrest in the radiology suite. This patient was successfully resuscitated and underwent embolization of the left internal iliac artery for hemostasis, followed by coil occlusion.

\section{Neonatal outcomes}

In neonates of women who received RA vs GA prior to their delivery, significantly higher median [IQR] Apgar scores were observed at both one minute (8 [8-9] vs 3 [0-5], respectively; median difference, $5 ; 95 \% \mathrm{CI}, 3$ to $8 ; P<$ $0.001)$ and five minutes (9 [9-9] vs 7 [0-9], respectively; median difference, $2 ; 95 \% \mathrm{CI}, 1$ to $9 ; P<0.001)$. In the 36 women receiving RA before delivery, seven $(19.4 \%)$ neonates and 0 neonates had an Apgar score $<7$ at one minute and five minutes, respectively. While in the 14 women receiving GA prior to delivery, 12 (86\%) neonates and six (43\%) neonates had an Apgar score $<7$ at one minute and five minutes, respectively. The mean (SD) gestational age of neonates was 35.5 (2.1) weeks in the RA group and 31.5 (5.9) weeks in the GA group. There were four cases of intrauterine death in the GA group, all with 
Table 4 Univariable factors associated with any packed red blood cell (PRBC) transfusion and increased number of PRBC transfusions

\begin{tabular}{|c|c|c|c|c|c|c|}
\hline \multirow[b]{2}{*}{ Variable } & \multicolumn{3}{|c|}{$\begin{array}{l}\text { Association with any PRBC transfusion in } \\
\text { logistic regression model }\end{array}$} & \multicolumn{3}{|c|}{$\begin{array}{l}\text { Association with increased number of PRBC } \\
\text { transfusions in linear regression model }\end{array}$} \\
\hline & Odds ratio & $95 \% \mathrm{CI}$ & $P$ value & Estimate* & $95 \% \mathrm{CI}$ & $P$ value \\
\hline Elective $\mathrm{CD}^{\$}$ & 0.06 & 0.01 to 0.24 & $<0.001$ & -3.280 & -4.733 to -1.827 & $<0.001$ \\
\hline Unplanned $\mathrm{CD}^{\$}$ & 18.86 & 4.25 to 83.59 & $<0.001$ & 3.280 & 1.827 to 4.733 & $<0.001$ \\
\hline Percreta ( $v s$ accreta and increta) & 1.03 & 0.33 to 3.16 & 0.96 & 0.769 & -0.933 to 2.471 & 0.38 \\
\hline GA ( $v s$ RA) & 1.96 & 0.56 to 6.85 & 0.29 & 2.335 & 0.615 to 4.054 & 0.01 \\
\hline Conversion to GA & 1.91 & 0.50 to 7.33 & 0.34 & 1.788 & -0.102 to 3.678 & 0.06 \\
\hline Cesarean hysterectomy & 5.68 & 1.46 to 22.12 & 0.01 & 2.024 & 0.199 to 3.848 & 0.03 \\
\hline Conservative management & 0.16 & 0.04 to 0.63 & 0.01 & -2.114 & -3.943 to -0.286 & 0.02 \\
\hline EBL (per $100 \mathrm{~mL}$ ) & 1.35 & 1.14 to 1.58 & $<0.001$ & 0.11 & 0.09 to 0.13 & $<0.001$ \\
\hline Phenylephrine use & 6.75 & 1.24 to 36.91 & 0.03 & 2.087 & -0.068 to 4.241 & 0.06 \\
\hline Early hemorrhage and DIC/coagulopathy & 1.48 & 0.13 to 17.50 & 0.76 & 0.780 & -2.822 to 4.382 & 0.67 \\
\hline Urological complications & 2.24 & 0.59 to 8.47 & 0.24 & 2.143 & 0.329 to 3.957 & 0.02 \\
\hline Longer OR time (per $30 \mathrm{~min}$ ) & 4.19 & 1.09 to 16.13 & 0.04 & 0.825 & 0.397 to 1.254 & $<0.001$ \\
\hline ICU admission & 5.21 & 0.58 to 47.10 & 0.14 & 4.618 & 2.506 to 6.730 & $<0.001$ \\
\hline Longer ICU stay (per day) & 3.90 & 0.59 to 25.67 & 0.16 & 2.103 & 0.723 to 3.303 & 0.002 \\
\hline
\end{tabular}

$\mathrm{CI}=$ confidence interval CD = Cesarean delivery; DIC = disseminated intravascular coagulation; $\mathrm{EBL}=$ estimated blood loss; $\mathrm{GA}=$ general anesthesia; ICU = intensive care unit, $\mathrm{OR}=$ operating room; $\mathrm{PRBC}=$ packed red blood cell; RA = regional anesthesia

\$ Includes Cesarean hysterectomies

* Parameter estimates represent the change in the number of transfused PRBC units associated with the presence of the risk factor (binary risk factors) or with each increase of 1 unit (unless otherwise indicated) in the risk factor (continuous risk factors)

early gestation and intrauterine growth retardation. In addition, one patient had an abruption and one had uterine rupture leading to fetal demise.

\section{Discussion}

Our data suggest that RA can be considered a safe and effective option for women with invasive placentation undergoing $\mathrm{CD}$ or CHyst in the setting of a multidisciplinary care approach. In women receiving RA vs GA, we found no differences in blood loss or blood transfusion. Furthermore, we observed superior neonatal outcomes, and no respiratory complications with RA.

At our hospital, there were approximately 70,000 deliveries during 2000-2012, with a steady increase in the rate of CDs from 24\% in 2000 to $35.9 \%$ in 2012. As expected, due to the tertiary nature of the program, the incidence of CDs at our centre is higher than the Canadian national average of $28.5 \%,{ }^{11}$ which in turn is higher than the UK national $\mathrm{CD}$ rate of $25.5 \% .^{12}$ The incidence of invasive placentation in our cohort was 71.4 per 100,000 deliveries or 1:1,400 over the period of 2000-2012. This is more than 1.5 times the incidence of $1: 2,272$ reported by Lilker et al. ${ }^{8}$ for our own institution during the period of 2000-2008. This incidence is half of that reported by Bailit et al. ${ }^{1}$ in the United States (1:731) for the periods 2008 and
2011. The most likely explanation for such an increase is an increased rate of external referrals of these patients. Over the last four years, we have received 41 referrals compared with 14 in the previous eight years, implying this as the predominant reason for an increased incidence at our institution.

The risk of developing placenta accreta increases with the number of previous CDs, ranging from $0.2 \%$ in women with no previous $\mathrm{CD}$ to $6.7 \%$ in those with five or more previous CDs. Furthermore, the risk increases substantially (to $67 \%$ ) with the presence of placenta previa, particularly if there is a history of four previous CDs with concurrent previa. ${ }^{13,14}$ Nevertheless, recent evidence shows a change in the epidemiology of invasive placentation. Bailit et al. ${ }^{1}$ found morbidly adherent placenta in $18 \%$ of nulliparous women and $37 \%$ in women with no prior CD. Other risk factors include advanced maternal age and any procedures that disrupt the integrity of the endometrium, including previous curettage, surgery for Asherman's syndrome, smoking, and multiparity. ${ }^{15}$ Ninety-one percent of our cohort had already undergone a $\mathrm{CD}$, and over half of the women had also undergone other uterine surgery. These figures can be compared with those of Miller et al. ${ }^{16}$ who investigated 62 cases of confirmed placenta accreta over nine years (1985-1994) and reported $73 \%$ with at least one CD. Forty-five percent of their patients were over the age of 35 years and $89 \%$ had concurrent placenta previa, rates 
that are similar to our study findings of $44 \%$ and $94 \%$, respectively.

The choice of anesthetic technique depends on many factors, including the state of emergency, hemodynamic stability, and the anesthesiologist's preference. Historically, concerns over massive hemorrhage and potential hemodynamic instability compounded by a sympathectomy from a regional block meant that most anesthesiologists would initially choose GA or convert from RA to GA during the operation after the fetus is delivered. Although many institutions report using GA for management of such cases, ${ }^{17,18}$ a few smaller studies have described good outcomes after the administration of RA. ${ }^{19,20}$ Our study represents one of the largest cohorts comparing these two anesthetic modalities for patients with invasive placentation. At our institution, the number of cases performed under RA was double that performed under GA, and the conversion rate from RA to GA was less than $10 \%$. This suggests that epidural anesthesia is acceptable in the management of these patients, even for those cases with deeper invasion of the placenta.

The majority of our cases had preoperative balloon insertion in the anterior division of the internal iliac artery. In our experience, there is a high interindividual variation in the hemostatic response to balloon inflation. While some patients show dramatic cessation of bleeding, others show no perceivable change. Accepting that iliac artery occlusion, in theory, should reduce arterial perfusion of the pelvis, we inflated the catheters in $83 \%$ of our patients within minutes after the delivery of the fetus. This was intended to provide temporary hemostasis until collaterals develop (usually within $20 \mathrm{~min}$ ). Approximately $66 \%$ of patients underwent embolization postoperatively at the discretion of the interventional radiologist for management of either active extravasation or evidence of excessive pelvic vascularity.

Various catheter-related complications have been reported in the literature. ${ }^{21}$ We have observed the need for re-embolization, ischemic buttocks and legs, rupture of the internal iliac artery, allergic reaction to radiocontrast agents in a small number of patients, as well as rare guidewire fracture. The cases of repeat embolization were seen in the earlier years when uterine conservation was the practice and women were considered at risk for postdelivery formation of arteriovenous malformations around the necrotic placental tissue.

An adherent placenta is associated with significant maternal morbidity and can lead to serious postpartum hemorrhage. This can trigger disseminated intravascular coagulation, multi-organ failure, and more challenging surgery with risks of damage to adjacent organs, including the bladder and intestines. As a result, the aggregate risk of maternal death may be as high as $7 \% .^{22}$ Due to a high incidence of complications associated with the conservative surgical technique (e.g., postpartum fever, hospital readmission, delayed hemorrhage, delayed hysterectomy, and repeat embolization), the surgical technique has changed over the years to adopt an elective CHyst approach. Overall, $72 \%$ of our patients underwent $\mathrm{CHyst}$, two-thirds under the RA technique and the remainder received GA. With this change, the use of uterotonics has similarly changed. The use of oxytocin and other uterotonic drugs has declined in recent years, and only half of our patients received prophylactic oxytocin intraoperatively. This is because, during a planned CHyst, the uterus is removed efficiently with the placenta in situ. There is no attempt, either manually or pharmacologically, to induce placental separation from what remains of the lower segment uterine wall, a technique shown to reduce blood loss. The overall rate of surgical complications was low in our cohort, except for urological complications ( $28 \%$ ), mainly due to the adherence of the placenta to the bladder. There was no difference in the rate of complications between the two groups, except for respiratory complications, all of which were seen in patients receiving GA.

Furthermore, neonatal outcome was superior in women receiving RA $v s$ those receiving GA prior to delivery. This finding is consistent with that of Lan et al. ${ }^{23}$ who found lower Apgar scores $(<7)$ in cases receiving GA $(33 \%)$ than in those receiving RA (14\%). Although other obstetric factors could be responsible, the use of GA induction agents and opioids prior to delivery can potentially impact the neonatal Apgar scores due to rapid placental transfer of the drugs to the fetus.

Our data provide evidence of a gradual shift in anesthetic management of women with invasive placentation from general to regional anesthesia. The shift has occurred in parallel with the change in surgical technique from conservative management to CHyst. Over the years, we have developed a protocol in our department -based on the existing literature ${ }^{24,25}$ and our own experience- for the anesthetic management of women with suspected invasive placentation (Appendix).

One of the limitations of our study is its retrospective nature, which depends on accurate recording of data. Although we think we captured all the important information, it is possible we may have missed some. From our data, we were unable to determine the impact of the exposure time and doses of general anesthetic drugs on the neonatal Apgar score. Future prospective randomizedcontrolled trials should be conducted to confirm the findings of our study. Nevertheless, our study highlights that, in the setting of multidisciplinary care, RA is a viable option for $\mathrm{CD}$ or CHyst, regardless of the depth of placental invasion, with minimal maternal and neonatal complications. 
In conclusion, after safely performing two-thirds of our CHyst cases under RA, our study suggests that, when compared with GA, RA is associated with no differences in blood loss or blood transfusion, superior neonatal outcome, and fewer maternal respiratory complications. Therefore, RA should be considered the primary anesthesia technique for such cases.

Acknowledgement The authors sincerely thank Kristi Downey MSc, perinatal research coordinator, for her invaluable collaboration in all stages of the research project, including research ethics board application, data interpretation, and elaboration of the manuscript.

Funding Institutional.

Competing interests No external funding and competing interests declared.

Author contributions Nhathien Nguyen-Lu and Mrinalini Balki contributed substantially to the acquisition and analysis of data and to the draft of the manuscript. Nhathien Nguyen-Lu, Mrinalini Balki, Jose Carlos, Almeida Carvalho, John Kingdom, Rory Windrim, and Lisa Allen contributed substantially to the conception and design of the manuscript and the interpretation of data. Jose Carlos, Almeida Carvalho, John Kingdom, Rory Windrim, and Lisa Allen contributed substantially to revising the article.

Editorial responsibility This submission was handled by Dr. Hilary P. Grocott, Editor-in-Chief, Canadian Journal of Anesthesia.

\section{Appendix}

Flowchart showing suggested anesthetic management of patients with invasive placentation. $\mathrm{ABG}=$ arterial blood gases; ICU = intensive care unit; MRI = magnetic resonance imaging; PCEA $=$ patient-controlled epidural anesthesia; $\mathrm{U} / \mathrm{S}=$ ultrasound. 
Mount Sinai Hospital anesthetic flowchart for the management of patients with invasive placentation undergoing planned cesarean delivery/cesarean hysterectomy

\section{Multidisciplinary Consultations}

- Maternal-Fetal Medicine [diagnosis] /Gynecology, including Urology [surgical planning] /Anesthesia /Interventional Radiology /Neonatology /Nursing [co-ordinator]

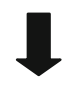

\section{Day before surgery}

- Secure cross match of 4 units of blood

- Arrange for cell saver technician

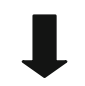

Morning of Cesarean Delivery - BEFORE Interventional Radiology

- Premedication: Metoclopramide10 mg IV, Famotidine 20mg IV and Gabapentin 600 mg PO

- Insertion of 2 large bore (>18G) cannulas - Ringer's Lactate $100 \mathrm{ml} / \mathrm{h}$

- Epidural catheter at L2/3 or 3/4 under U/S guidance, confirm catheter placement with TSUI test or $3 \mathrm{ml} 2 \%$ Lidocaine

- Insertion of Foley catheter

Interventional Radiology suite (one hour prior to surgery)

- Trans-femoral placement of bilateral intra-arterial balloons in proximal anterior divisions of internal iliac arteries

- Insertion of radial arterial line

\section{Main Operating Room - Pre-operative}

- Administration of Sodium Citrate $30 \mathrm{mmol} / \mathrm{L} \mathrm{PO}$

- IV antibiotics (Cefazolin $2 \mathrm{~g}$ )

- Check 4 units of blood is available in the room for transfusion

- Set up cell saver

- Top up of epidural - Lidocaine $2 \%$ or Bupivacaine $0.5 \%+1: 200,000$ Epinephrine + Fentanyl $50-100$ mcg (Increments of $5 \mathrm{ml}$ to achieve T4 block to cold bilaterally)

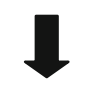

Main Operating Room - Intra-operative

- Estimation of blood loss (weighing of sponges, recovery from cell saver)

- ABG sampling, full blood count and coagulation as required

- Good communication with surgeons and patient

- Inflation of intra-arterial balloons on request

- Avoid uterotonics during cesarean hysterectomy (as placenta not separated or removed)

- Tranexamic acid $1 \mathrm{~g} \mathrm{IV}$

- Epidural Morphine $2.5 \mathrm{mg}$

Back to Interventional Radiology Dept - Post-operative Embolization

- Top up of epidural using small increments of $5 \mathrm{ml}$ of $0.5 \%$ Bupivacaine or $2 \%$ Lidocaine for embolization if required

\section{Post-embolization - Return to Labor \& Delivery /ICU}

- PCEA -Plain Bupivacaine 0.125\% + Fentanyl $2 \mathrm{mcg} / \mathrm{mL}$ - infusion $10 \mathrm{ml} / \mathrm{h}$, demand bolus $5 \mathrm{ml}$, lockout $10 \mathrm{~min}$

- Start regular Acetaminophen 1g QID PO, Gabapentin 200mg TID PO for 48 hours, morphine 10 mg PO PRN, Diclofenac $50 \mathrm{mg}$ TID (if not contraindicated)

- If coagulation results normal and surgical team satisfied with hemostasis, then removal of epidural catheter by anesthetist and femoral catheters by radiologist by 24 hours post-partum. 


\section{References}

1. Bailit JL, Grobman WA, Rice MM, et al. Morbidly adherent placenta treatments and outcomes. Obstet Gynecol 2015; 125: 683-9.

2. Knight M, Kurinczuk JJ, Spark P, Brocklehurst P. United Kingdom Obstetric Surveillance System Steering Committee. Cesarean delivery and peripartum hysterectomy. Obstet Gynecol 2008; 111: 97-105.

3. Wu S, Kocherginsky M, Hibbarb JU. Abnormal placentation: twenty-year analysis. Am J Obstet Gynecol 2005; 192: 1458-61.

4. Engelbrechtsen L, Langhoff-Roos J, Joergen Kjer J, Istre $O$. Placenta accreta: adherent placenta due to Asherman syndrome. Clin Case Rep 2015; 3: 175-8.

5. Bauer ST, Bonanno C. Abnormal placentation. Semin Perinatol 2009; 33: 88-96.

6. Garmi G, Goldman S, Shalev E, Salim R. The effects of decidual injury on the invasion potential of trophoblastic cells. Obstet Gynecol 2011; 117: 55-9.

7. Walker $M G$, Allen L, Windrim RC, et al. Multidisciplinary management of invasive placenta previa. J Obset Gynaecol Can 2013; 35: 417-25.

8. Lilker SJ, Meyer RA, Downey KN, Macarthur AJ. Anesthetic considerations for placenta accreta. Int J Obstet Anesth 2011; 20: 288-92.

9. Warshak $C R$, Eskander $R$, Hull AD, et al. Accuracy of ultrasonography and magnetic resonance imaging in the diagnosis of placenta accreta. Obstet Gynecol 2006; 108: 573-81.

10. Tsui BC, Gupta S, Finucane B. Confirmation of epidural catheter placement using nerve stimulation. Can J Anaesth 1998; 45: 6404.

11. Canadian Institute for Health Information. Highlights of 20112012 Selected Indicators Describing the Birthing Process in Canada; June 2012. Available from URL: https://secure.cihi.ca/ free_products/Childbirth_Highlights_2010-11_EN.pdf (accessed May 2016).

12. Health \& Social Care Information Centre. Hospital Episode Statistics: NHS Maternity Statistics - 2012-13 - Summary report. Available from URL: http://www.hscic.gov.uk/catalogue/ PUB12744/nhs-mate-eng-2012-13-summ-repo-rep.pdf (accessed May 2016).

13. Silver RM, Landon $M B$, Rouse DJ, et al. Maternal morbidity associated with multiple repeat caesarean deliveries. Obstet Gynecol 2006; 107: 1226-32.
14. Clark SL, Koonings PP, Phelan JP. Placenta previa/accreta and prior cesarean section. Obstet Gynecol 1985; 66: 89-92.

15. Garmi G, Salim R. Epidemiology, etiology, diagnosis and management of placenta accreta. Obstet Gynecol Int 2012. DOI:10.1155/2012/873929.

16. Miller DA, Chollet JA, Goodwin TM. Clinical risk factors for placenta-previa placenta accreta. Am J Obstet Gynecol 1997; 177: $210-4$

17. Weiniger $C F$, Einav S, Deutsch L, Ginosar Y, Ezra Y, Eid L. Outcomes of prospectively-collected consecutive cases of antenatal-suspected placenta accreta. Int J Obstet Anesth 2013; 22: 273-9.

18. Mok M, Heidemann B, Dundas K, Gillespie I, Clark V. Interventional radiology in women with suspected placenta accreta undergoing caesarean section. Int J Obstet Anesth 2008; 17: $255-61$.

19. Sadashivaiah JW, Wilson R, Thein A, McLure H, Hammond CJ, Lyons $G$. Role of prophylactic uterine artery balloon catheters in the management of women with suspected placenta accreta. Int $\mathbf{J}$ Obstet Anesth 2011; 20: 282-7.

20. Fuller AJ, Carvalho B, Brummel C, Riley ET. Epidural anesthesia for elective cesarean delivery with intraoperative arterial occlusion balloon catheter placement. Anesth Analg 2006; 102: 585-7.

21. Bishop S, Butler K, Monaghan S, Chan K, Murphy G, Edozien L. Multiple complications following the use of prophylactic internal iliac artery balloon catheterisation in a patient with placenta percreta. Int J Obstet Anesth 2011; 20: 70-3.

22. Kayem $G$, Deneux-Tharaux $C$, Sentilhes $L$. PACCRETA group. PACCRETA: clinical situations at high risk of placenta ACCRETA/percreta: impact of diagnostic methods and management on maternal morbidity. Acta Obstet Gynecol Scand 2013; 92: 476-82.

23. Lan JY, Wang MH, Fan SZ, Chen $L K$. Impact of anesthetic methods on neonatal outcome in women receiving temporary balloon occlusion of the common iliac artery during cesarean section for placenta accreta. Taiwan J Obstet Gynecol 2011; 50: 515-7.

24. Royal College of Obstetricians \& Gynaecologists. Placenta Praevia, Placenta Praevia Accreta and Vasa Praevia: Diagnosis and Management (Green-top Guideline No. 27) - January 2011. Available from URL: https://www.rcog.org.uk/globalassets/ documents/guidelines/gtg_27.pdf (accessed May 2016).

25. Committee on Obstetric Practice. Committee opinion no. 529: placenta accreta. Obstet Gynecol 2012; 120: 207-11. 